\title{
CHEMICAL STUDIES ON MEMORY FIXATION IN GOLDFISH*
}

\author{
BERNARD W. AGRANOFF, ROGER E. DAVIS** AND JOHN J. BRINK** \\ Mental Health Research Institute and Department of Biological Chemisiry, University of Michigan,
} Ann Arbor, Mich. (U.S.A.)

(Received December 13th, 1965)

A striking characteristic of this decade in biochemistry is the introùction of selective blocking agents as tools for research. A major area of application has been in studies on nucleic acid and protein synthesis ${ }^{1}$. As findings in diverse areas are correlated, the details of the selective nature of these toxic substances become known, adding to their value.

The use of selective blocking agents in behavioral experiments has been reported by several laboratories. Dingman and Sporn8 injected 8-azaguanine intracisternally into rats in an attempt to block learning. Chamberlain et al. ${ }^{5}$ reported that intraperitoneally injected 8-azaguanine prolonged the time during which asymmetry of the limbs of rats became fixed following section of the spinal cord. Barondes and Jarvik $^{4}$ recently found that intracerebral injection of actinomycin D into mice had no specinic behavioral effect. These reports were of interest because of the putative role of 8-azaguanine and actinomycin D in blocking the synthesis of RNA. In 1963, Flexner et al. ${ }^{10}$ reported an effect of puromycin on memory in mice. This study wili be discussed later in connection with work in our laboratory with goidfish. Puromycin is a naturally-occurring nucleoside-amino acid which has been reported to block selectively protein synthesis. A mechanism has been proposed for its action which is based on the structural similarity between puromycin and the aminoacyl-adenosine terminus of transfer-RNA ${ }^{15}$. Experimental results indicate that the forming peptide chain combines with puromycin instead of the next aminoacyl-transfer-RNA and that the forming peptide is released from the ribosome prematurely as peptidyl puromycin $^{12,13}$.

Interest in memory at the biological laboratories of the Mental Health Research Institute was stimulated to a large extent by Ralph W. Gerard, former director of laboratories, whosi continued interest in this work is gratefully acknowledged. For the past two years, we have been studying biochemical correlates of memory in

* Text of a talk presented at the 132nd meeting of the American Association for the Advancement of Science, Berkeley, Calif. (U.S.A.), December 27, 1965. The resiarch was sponsored by a grant from The National Science Foundation.

** Interdisciplinary training fellow under USPHS training grant No. 5T7-MH-7417.

Brain Research, 1 (1966) 303-309 
Carrassius auratus, the goldfish. From the literature, we learned that goldfish were capable of learning shock avoidance as well as other tasks, and appeared to have long-term memory of their training ${ }^{11}$. This animal has several other experimental advantages. Since teleosts are poikilotherms, it becomes easy to investigate the effect of temperature on behavioral phenomena. The small size of the goldfish makes it potentially suitable for autoradiographic studies, since the exposure time for development of histologic sections is largely a function of the amount of isotope injected per unit body weight. The goldfish brain is easily exposed for surgical procedures, and surgery is well-tolerated. We were able to devise a simple technique ${ }^{3}$ for the rapid injection of drugs intracranially (over, not into the brain) without the use of anesthetics.

In the experiments presented here, we used a shuttle box similar to one described by Bitterman ${ }^{11}$. Goldfish are placed in individual tanks divided into two compartments
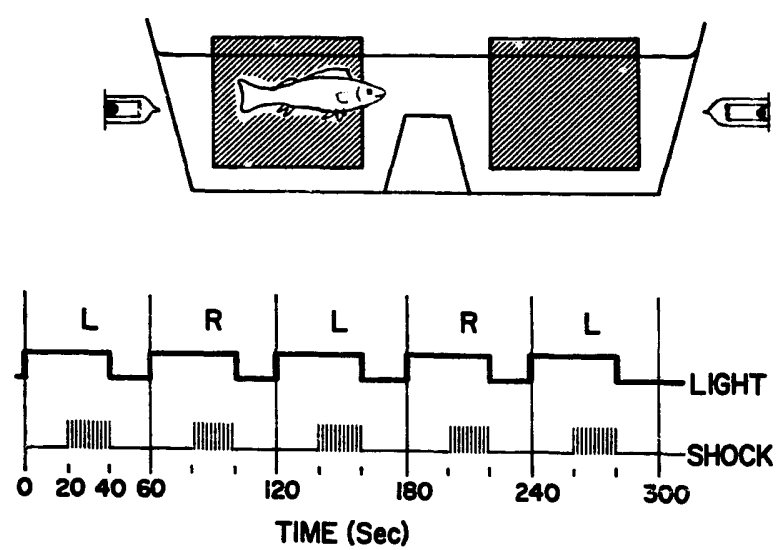

Fig. 1. Diagrammatic representation of goldfish shuttle box and trial sequence.

by an underwater barrier (Fig. 1). At the start of a trial, a light is turned on at the end of the tank in which the fish has been placed. Twenty seconds later, an intermittent electric shock is applied to the illuminated end of the tank for an additional 20 sec. During this period, fish that have not already swum over the barrier, do so, escaping further shock. Forty seconds after the start of the trial, light and shock are both terminated. After $20 \mathrm{sec}$ of intertrial interval, in which there is no light or shock, the opposite end of the tank is illuminated and the procedure is repeated. Fish receive 5 trials in 5 min. A block of 5 trials as outlined in Fig. 1 is followed by 5 min of rest in darkness. In this way fish receive 20 trials in $\mathbf{4 0} \mathrm{min}$ on the first day of the experiment. If a fish swims over the barrier with the light stimulus alone and thus avoids being shocked, a correct response is scored for that trial. Groups of fish usually score up to $30 \%$ correct responses during the first 10 trials, and improve during the second 10 trials. If they are immediately given an additional set of 10 trials, they do still better. If we now interpose a time interval between trial 20 and 21 such as an hour, a day, a week, or a month, there is little effect on the scores for the last 10 trials. Thus we see 
that the goldfish has good memory of the task. In our experiments, we use an interval of 3 days between trial 20 and 21 . Fish receive 20 trials on day 1 and 10 trials on day 4 . In our initial studies, we compared the effect of electroconvulsive shock and intracranial injections of puromycin following the 20 trials on day 1 on the performance observed on day 4 . We found that each of these agents produced a partial memory deficit if given immediately after trial 20 , but had no effect if given 2 h later ${ }^{6,7}$. In each instance, memory was measured as the performance for the 10 trials on day 4. Using electroconvulsive shock as the agent which blocks memory fixation, we studied the effect of water teinperature during the period immediately following trial 20 on the rate of memory fixation. We found that cooling extended the period of time during which electroconvulsi ie shock can block memory, ${ }^{6,7}$. This result is similar to that reported in mammals ${ }^{14}$, but is of particular interest in that we used a poikilotherm, simplifying interpretation of the results.

During the course of these experiments, we introduced a regression analysis for the evaluation of memory on day 4 . The regression of the total day 1 score on the day 4 score, derived from data for 129 control fish, is used to predict day 4 scores for experimental fish. The predicted score $(P)$ of a fish is subtracted from the score the fish achieves (A) on day 4, and the result is called the retention score (A-P); a retention score of zero signifies normal memory. This technique compensates for uncontrolled differences in levels of responding between fish. Conclusions reached by evaluating retention scores or raw day 4 scores have been identical, but the retention scores have been more consistent.

We have recently found ${ }^{2}$ that by increasing the amount of puromycin injected we can obliterate memory of the avoidance response on day 4 (the score for the 10 trials on day 4 is not significantly different from the score in the first 10 trials on day 1). Injection of $170 \mu \mathrm{g}$ of puromycin immediately after trial 20 on day 1 produces a complete memory deficit on day 4 . If we wait $1 \mathrm{~h}$ after trial 20 before injecting, the drug has no detectable effect on memory (Table 1). The dramatic change in susceptibility of memory on day 4 to puromycin injected during the hour following the trials on day 1 is indicated by ihe graph of retention scores in Fig. 2A. These results

\section{TABLE I}

EFTECT OF PUROMYCIN INJECTED AFTER TRAINING ON MEMORY

\begin{tabular}{|c|c|c|c|c|c|c|}
\hline \multirow[t]{2}{*}{ No. } & \multicolumn{2}{|c|}{ Trials day 1} & \multirow[t]{2}{*}{ Treatment } & \multicolumn{3}{|c|}{ Trials day 4} \\
\hline & $1-10$ & $11-20$ & & $\begin{array}{l}21-30 \\
A\end{array}$ & $\begin{array}{l}21-30 \\
P\end{array}$ & $\begin{array}{l}\text { Retention } \\
\text { score } \\
(A-P)\end{array}$ \\
\hline $\begin{array}{l}72 \\
36\end{array}$ & $\begin{array}{l}2.3 \\
2.5\end{array}$ & $\begin{array}{l}3.4 \\
3.8\end{array}$ & $\begin{array}{l}\text { Uninjected } \\
\text { Puromycin dihydrochloride } \\
170 \mu \mathrm{g}, \text { immediate }\end{array}$ & $\begin{array}{l}5.3 \\
2.7\end{array}$ & $\begin{array}{l}5.3 \\
5.4\end{array}$ & $\begin{array}{l}0 \\
-2.7\end{array}$ \\
\hline 35 & 2.5 & 4.6 & $\begin{array}{l}\text { Puromycin dihydrochloride } \\
170 \mu \mathrm{g}, 60 \text { min delay }\end{array}$ & 5.5 & 5.6 & -0.1 \\
\hline
\end{tabular}



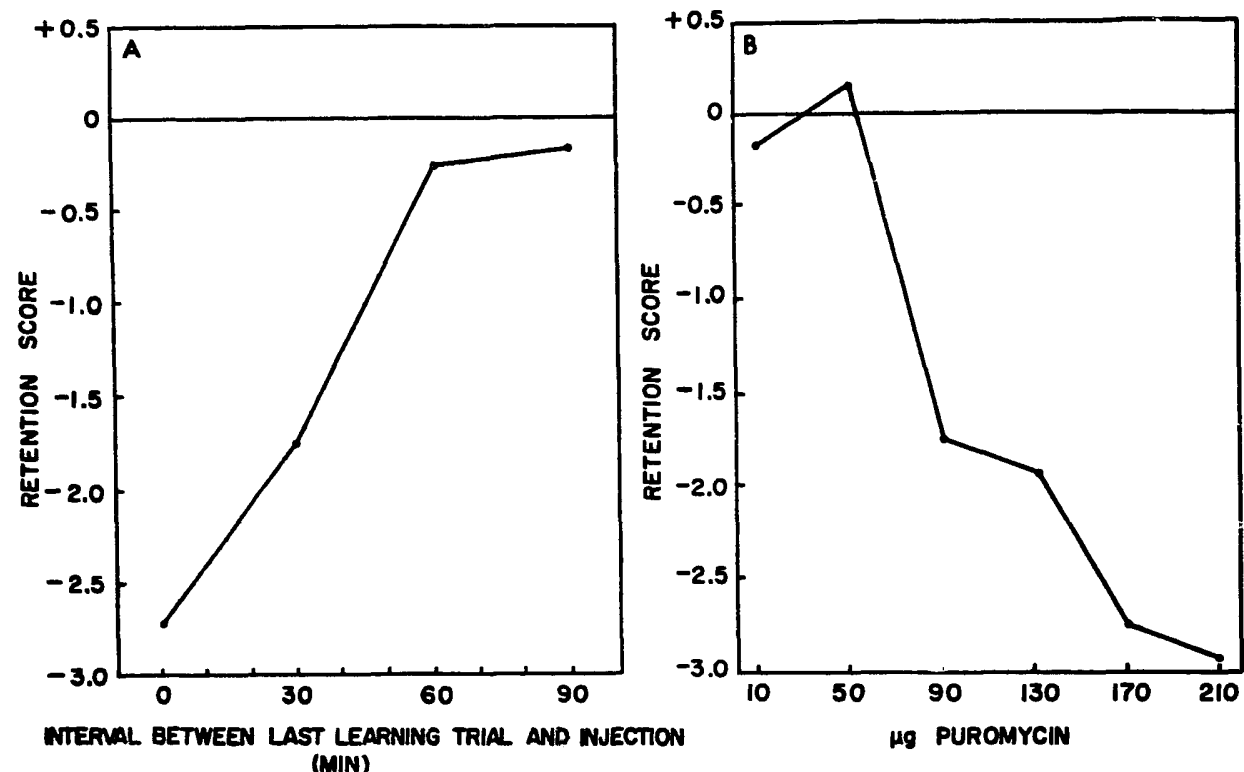

WTERAL BETWEEN LAST LEARNING TRIAL AND MJECTON
(MIN)

Hg PUROMYCIN

Fig. 2. (A) Effect on the retention score of the time of injection of $170 \mu \mathrm{g}$ of puromycin following trial 20. (B) Effect on the retention score of the dose of puromycin injected immediately after trial 20.

indicate that memory on day 4 depends on a fixation process occurring after the trials on day 1 which is disrupted by puromycin. The effect of different amounts of puromycin injected immediately after trial 20 is shown in Fig. 2B. Injection of $50 \mu \mathrm{g}$ or less has no significant effect, while $90 \mu \mathrm{g}$ or more produces memory deficits. Memory is not affected by injection of physiological saline, nor is it affected by puromycin aminonucleoside or $O$-methyltyrosine (methoxyphenylalanine), two moieties which comprise the puromycin molecule (Table II).

Puromycin can be injected into fish rapidly and without anesthesia. There is no transient drowsiness or other evidence of neurological disorder. We have found that fish given puromycin shortly before the 20 trials on day 1 show the usual increase in

TABLE II

EFFECT OF PUROMYCIN MOIETIES ON MEMORY

\begin{tabular}{|c|c|c|c|c|c|c|}
\hline \multirow[t]{2}{*}{ No. } & \multicolumn{2}{|c|}{ Trials day 1} & \multirow[t]{2}{*}{ Treatment } & \multicolumn{3}{|c|}{ Trials day 4} \\
\hline & $1-10$ & $11-20$ & & $\begin{array}{l}21-30 \\
A\end{array}$ & $\begin{array}{l}21-30 \\
P\end{array}$ & $\begin{array}{l}\text { Retention } \\
\text { score } \\
(A-P)\end{array}$ \\
\hline 23 & 2.0 & 3.2 & $\begin{array}{l}\text { Puromycin aminonucleoside } \\
90 \mu \mathrm{g}, \text { immediate }\end{array}$ & 5.1 & 5.0 & +0.1 \\
\hline 81 & 2.5 & 3.5 & $\begin{array}{l}O \text {-Methyltyrosine hydrochloride } \\
70 \mu \mathrm{g} \text {, immediate }\end{array}$ & 5.2 & 5.4 & -0.2 \\
\hline
\end{tabular}


TABLE III

EFFECT OF PUROMYCIN INJECTED BEFORE TRAINING ON MEMORY

\begin{tabular}{|c|c|c|c|c|c|c|}
\hline \multirow[t]{2}{*}{ No. } & \multicolumn{2}{|c|}{ Trials day 1} & \multirow[t]{2}{*}{ Treaiment } & \multicolumn{3}{|c|}{ Trials day 4} \\
\hline & $1-10$ & $11-20$ & & $\begin{array}{l}21-30 \\
A\end{array}$ & $\begin{array}{l}21-30 \\
P\end{array}$ & $\begin{array}{l}\text { Retention } \\
\text { score } \\
(A-P)\end{array}$ \\
\hline 39 & 3.0 & 3.8 & $\begin{array}{l}\text { Puromycin dihydrochloride } \\
170 \mu \mathrm{g}, 1 \mathrm{~min} \text { pretrial }\end{array}$ & 3.3 & 5.5 & -2.2 \\
\hline 35 & 2.4 & 3.3 & $\begin{array}{l}\text { Puromycin dihydrochloride } \\
170 \mu \mathrm{g}, 20 \text { min pretrial }\end{array}$ & 4.2 & 5.2 & -1.0 \\
\hline
\end{tabular}

correct responses from trials $1-10$ to $11-20$, while their memory on day 4 is deficient (Table III). Thus puromycin does not affect that aspect of memory which is manifested in the improvement in performance on day 1 ; what we define as short-term memory. We see then that puromycin produces deficits in memory on day 4 by acting specinically on the process by which long-term memory is fixed. A summary of these experiments is seen in Fig. 3.

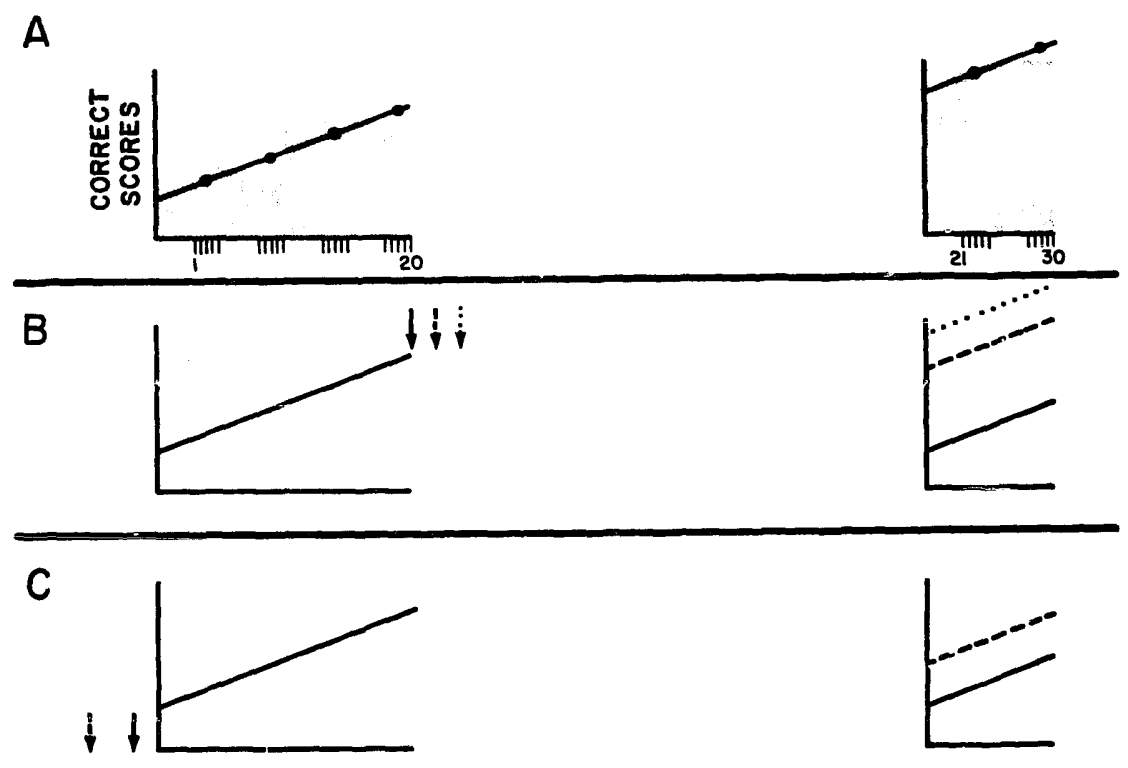

Fig. 3. Diagrammatic summary of our experiments on memory. (A) Fish are given 20 trials on day 1 in blocks of 5 and 10 trials on day 4. The shaded areas represent each 10 trials for which means and standard errors are determined. A predicted score for trials $21-30$ is subtracted from the achieved score. (B) Puromycin injected immediately following trial 20 reduces performance on day 4 to the naive level. Puromycin injected $1 \mathrm{~h}$ later, has no effect. (C) Puromycin injected immediately before trial 1 appears to have no effect on the increase in performance on day 1 (short-term memory), but nevertheless biocks memory fixation. When puromycin is injected $20 \mathrm{~min}$ before trials, short-term memory is unimpaired, and some fixation occurs. 
A question before us is what is the relationship between the behavioral effect of puromycin and its role as an inhibitor of protein synthesis? We have performed experiments in which puromycin was injezted intracranially into groups of fish and then at various times later, leucine- ${ }^{3} \mathrm{H}$ was injected intraperitoneally. Thirty minutes after the leucine injection, the brains were removed and analysed for protein radioactivity. While we see a marked inhibition of leucine incorporation into brain protein for hours after the puromycin injection, we cannot as yet claim a simple correlation between the biochemical and behavioral effects of puromycin. These experiments must be tempered by such questions as whether puromycin acts at a specific locus, and whether a specific protein mediates the behavioral effect. We measure total acidprecipitable protein, and do not see the dynamic effect of the drug on the family of proteins turning over in the brain, each with a unique time constant. We have evidence that another in vivo inhibitor of brain protein synthesis, acetoxycycloheximide, also causes a memory deficit (Table IV). $0.1 \mu \mathrm{g}$ of the drug produces a partial memory

TABLE IV

EFFECT OF ACETOXYCYCLOHEXIMIDE* INJECTED AFTER TRAINING ON MEMORY

\begin{tabular}{|c|c|c|c|c|c|c|}
\hline \multirow[t]{2}{*}{ No. } & \multicolumn{2}{|c|}{ Trials day 1} & \multirow[t]{2}{*}{ Treatment } & \multicolumn{3}{|c|}{ Trials day 4} \\
\hline & $1-10$ & $11-20$ & & $\begin{array}{l}21-30 \\
A\end{array}$ & $\begin{array}{l}21-30 \\
P\end{array}$ & $\begin{array}{l}\text { Retention } \\
\text { score } \\
(A-P)\end{array}$ \\
\hline 30 & 1.7 & 2.7 & $\begin{array}{l}\text { Acetoxycycloheximide } \\
0.1 \mu \mathrm{g}, \text { immediate }\end{array}$ & 3.2 & 5.1 & -1.9 \\
\hline 36 & 0.89 & 2.2 & $\begin{array}{l}\text { Acetoxycycloheximide } \\
0.1 \mu \mathrm{g}, 6 \mathrm{~h} \text { delay }\end{array}$ & 4.8 & 4.7 & +0.1 \\
\hline
\end{tabular}

* Generously donated by Dr. T. J. McBride, Chas. Pfizer \& Co., Maywood, N. J. (U.S.A.).

deficit, but blocks incorporation of leucine- ${ }^{3} \mathrm{H}$ into protein more profoundly than 170 $\mu \mathrm{g}$ of puromycin. This apparent difference between two potent inhibitors of protein synthesis may prove to be an important tool in the elucidation of the behavioral effect of puromycin.

More significant is the fact that two structurally unrelated substances, both of which exert their antibiotic effect by selectively blocking protein synthesis, affect memory. Thus protein synthesis is further implicated as an obligatory step in memory formation.

A few words about memory and time constants. In studies with mice, Flexner et al. report that recent, or short-term memory can be destroyed by bilateral temporal injections into the brain substance of puromycin 3-6 days after a learning experience, while older memory can be destroyed 6 weeks after learning by injections into bilateral frontal and ventricular sites as wel19,10. Comparison of these studies with our work on goldfish are complicated by differences between the mouse and goldfish nervous system, the mode of injection, and the training tasks. In the mouse, short- 
and long-term memory are distinguished by differences in the effective site of puromycin injection. Both short- and long-term memory are reportedly destroyed by puromycin. Short- and long-term memory in the goldfish are distinguished by puromycin susceptibility during formation. Short-term memory may be measured in days, but it cannot be transferred to long-term memory after an hour following training. Formed long-term memory does not appear to be puromycin-susceptible in our experiments. Long-term memory in goldfish, once formed, does not appear to turn over, but rather like genetic and immunological information, it is stored in what appears to be a metabolically inert form.

\section{SUMMARY}

Puromycin and acetoxycycloheximide, antibiotics known to block selectively protein synthesis, also block the formation of memory of shock avoidance in the goldfish.

\section{REFERENCES}

1 Symposium, Antimetabolites Affecting Protein or Nucleic Acid Synthesis, 48th Annual Meeting of the Federation of American Societies for Experimental Biology, Fed. Proc., 23, part I (1964) 940-989.

2 Agranoff, B. W., Davis, R. E., and Brink, J. J., Memory fixation in the goldfish, Proc. nat. Acad. Sci. (Wash.), 54 (196j) 788-793.

3 Agranoff, B. W., and Klinger, P. L., Puromycin effect on memory fixation in the go!dfish, jcience, 146 (1964) 952-953.

4 Barondes, S. H., AND JARVIK, M. E., The influence of actinomycin-D on brain RNA synthesis and on memory, $J$. Neurochem., 11 (1964) 187-195.

5 Chamberlain, T. J., Rothschild, G. H., AND Gerard, R. W., Drugs affecting RNA and learning, Proc. nat. Acad. Sci. (Wash.), 49 (1963) 918-924.

6 DAVIS, R. E., AND AGRaNofF, B. W., Effect of electroccunvulsive shock and of puromycin on memory in goldfish, Fed. Proc., 24 (1965) 329.

7 DAvis, R. E., BRight, P. J., AND AGRANOFF, B. W., Effect of ECS and puromycin on memory in fish, J. comp. physiol., Psychol. 60 (1965) 162166.

8 DINGMAN, W., AND SPORN, M. B., The incorporation of 8-azaguanine into rat brain RNA and its effect on maze-learning by the rat: An inquiry into the biochemical basis of memory, $J$. psychiat. Res., 1 (1961) 1-11.

9 FleXner, L. B., Flexner, J. B., de la Haba, G., AND Roberts, R. B., Loss of memory as related to inhibition of cerebral protein s:nthesis, J. Neurochem., 12 (1965) 535-541.

10 Flexner, J. B., Flexner, L. B., AND STellar, E., Memory in mice as affected by intracerebral puromycin, Science, 141 (1963) 57-59.

11 Horner, J. L., Longo, N., AND Bitterman, M. E., A shuttle box for fish and a control circuit of general applicability, Amer. J. Psychol., 74 (1961) 114-120.

12 Morris, A., Favelukes, S., ARlinghaus, R., AND Schweet, R., Mechanism of puromycin inhibition of hemcglobin synthesis, Biochem. biophys. Res. Commun., 7 (1962) 326-330.

13 Nathans, D., Puromycin inhibition of protein synthesis: Incorporation of puromycin into peptide chains, Proc. nat. Acad. Sci. (Wash.), 51 (1964) 585-592.

14 RANSmeIER, R. E., AND GeRARD, R. W., Effects of temperature, convulsion and metabolic factors on rodent memory and EEG, Amer. J. Physiol., 179 (1954) 663-664.

15 YARMOLINSKY, M. B., AND DE LA HABA, G. L., Inhibition by puromycin of amino acid incorporation into protein, Proc. nat. Acad. Scl. (Wash.), 45 (1959) 1721-1729. 